OPEN ACCESS

Edited by:

Yurong Lai,

Gilead, United States

Reviewed by:

Kit Wun Kathy Cheung, Genentech, Inc., United States

Richard McNeill,

Canterbury District Health Board,

New Zealand

Young Hee Choi,

Dongguk University Seoul, South

Korea

*Correspondence:

Pajaree Chariyavilaskul pajaree.|@chula.ac.th

Specialty section:

This article was submitted to Drug Metabolism and Transport,

a section of the journal

Frontiers in Pharmacology

Received: 17 June 2021 Accepted: 01 September 2021 Published: 17 September 2021

Citation:

Rattanacheeworn P, Kerr SJ, Kittanamongkolchai $W$,

Townamchai N, Udomkarnjananun S, Praditpornsilpa $K$,

Thanusuwannasak T, Udomnilobol U, Jianmongkol S, Ongpipattanakul B,

Prueksaritanont T, Avihingsanon $Y$ and

Chariyavilaskul P (2021) Quantification of CYP3A and Drug Transporters Activity in Healthy Young, Healthy Elderly and Chronic Kidney Disease Elderly Patients by a Microdose

Cocktail Approach.

Front. Pharmacol. 12:726669. doi: 10.3389/fphar.2021.726669

\section{Quantification of CYP3A and Drug Transporters Activity in Healthy Young, Healthy Elderly and Chronic Kidney Disease Elderly Patients by a Microdose Cocktail Approach}

Punyabhorn Rattanacheeworn ${ }^{1}$, Stephen J Kerr ${ }^{2}$, Wonngarm Kittanamongkolchai ${ }^{3}$, Natavudh Townamchai ${ }^{4}$, Suwasin Udomkarnjananun ${ }^{4}$, Kearkiat Praditpornsilpa ${ }^{4,5}$, Thanundorn Thanusuwannasak ${ }^{6}$, Udomsak Udomnilobol ${ }^{7}$, Suree Jianmongkol ${ }^{6,8}$, Boonsri Ongpipattanakul ${ }^{6,9}$, Thomayant Prueksaritanont $^{7}$, Yingyos Avihingsanon ${ }^{1,4}$ and Pajaree Chariyavilaskul ${ }^{1,10 *}$

\footnotetext{
'Clinical Pharmacokinetics and Pharmacogenomics Research Unit, Chulalongkorn University, Bangkok, Thailand, ${ }^{2}$ Biostatistics Excellence Center, Faculty of Medicine, Chulalongkorn University, Bangkok, Thailand, ${ }^{3}$ Maha Chakri Sirindhorn Clinical Research Center Under the Royal Patronage, Research Affairs, Faculty of Medicine, Chulalongkorn University, Bangkok, Thailand, ${ }^{4}$ Division of Nephrology, Department of Medicine, Faculty of Medicine, Chulalongkorn University, Bangkok, Thailand, ${ }^{5}$ Excellent Center of Geriatrics, King Chulalongkorn Memorial Hospital, Thai Red Cross Society, Bangkok, Thailand, ${ }^{6}$ Chulalongkorn University Drug and Health Products Innovation Promotion Center, Faculty of Pharmaceutical Sciences, Chulalongkorn University, Bangkok, Thailand, ${ }^{7}$ Chulalongkorn University Drug Discovery and Drug Development Research Center, Chulalongkorn University, Bangkok, Thailand, ${ }^{8}$ Department of Pharmacology and Physiology, Faculty of Pharmaceutical Sciences, Chulalongkorn University, Bangkok, Thailand, ${ }^{9}$ Department of Biochemistry and Microbiology, Faculty of Pharmaceutical Sciences, Chulalongkorn University, Bangkok, Thailand, ${ }^{10}$ Department of Pharmacology, Faculty of Medicine, Chulalongkorn University, Bangkok, Thailand
}

Background: Ageing and chronic kidney disease (CKD) affect pharmacokinetic (PK) parameters. Since mechanisms are related and remain unclear, cytochrome P450 (CYP) $3 \mathrm{~A}$ and drug transporter activities were investigated in the elderly with or without CKD and compared to healthy adults using a microdose cocktail.

Methods: Healthy young participants $(n=20)$, healthy elderly participants $(n=16)$ and elderly patients with CKD $(n=17)$ received, in study period 1, a single dose of microdose cocktail probe containing $30 \mu \mathrm{g}$ midazolam, $750 \mu \mathrm{g}$ dabigatran etexilate, $100 \mu \mathrm{g}$ atorvastatin, $10 \mu \mathrm{g}$ pitavastatin, and $50 \mu \mathrm{g}$ rosuvastatin. After a 14-day wash-out period, healthy young participants continued to study period 2 with the microdose cocktail plus rifampicin. PK parameters including area under the plasma concentrationtime curve $(A \cup C)$, maximum plasma drug concentration $\left(C_{\max }\right)$, and half-life were estimated before making pairwise comparisons of geometric mean ratios (GMR) between groups.

Results: AUC and $\mathrm{C}_{\max }$ GMR (95\% confidence interval; $\mathrm{Cl}$ ) of midazolam, a CYP3A probe substrate, were increased 2.30 (1.70-3.09) and 2.90 (2.16-3.88) fold in healthy elderly and elderly patients with $C K D$, respectively, together with a prolonged half-life. $A \cup C$ and $C_{\max }$ GMR $(95 \% \mathrm{Cl})$ of atorvastatin, another CYP3A substrate, was increased 2.14 (1.52-3.02) fold in healthy elderly and 4.15 (2.98-5.79) fold in elderly patients with CKD, indicating 
decreased CYP3A activity related to ageing. Associated AUC changes in the probe drug whose activity could be modified by intestinal P-glycoprotein (P-gp) activity, dabigatran etexilate, were observed in patients with CKD. However, whether the activity of pitavastatin and rosuvastatin is modified by organic anion transporting polypeptide 1B (OATP1B) and of breast cancer resistance protein (BCRP), respectively, in elderly participants with or without CKD was inconclusive.

Conclusions: CYP3A activity is reduced in ageing. Intestinal P-gp function might be affected by CKD, but further confirmation appears warranted.

Clinical Trial Registration: http://www.thaiclinicaltrials.org/ (TCTR 20180312002 registered on March 07, 2018)

Keywords: pharmacokinetics, microdose cocktail, cytochrome P450, drug transporters, elderly, chronic kidney disease

\section{INTRODUCTION}

Chronic kidney disease (CKD) is a significant public health problem worldwide, impacting national health expenditures and patient morbidity and mortality (United Nations, 2020). The overall prevalence of $\mathrm{CKD}$ in the Thai population is remarkably high (17.5\% of the population), and the prevalence increases with advancing age (Ingsathit et al., 2009). Thailand is currently in a significant demographic shift, with a rapid increase in the ageing population and the elderly, defined in this study as those aged $>60$ years (World Health Organization, 2015). Due to physiological changes in the elderly, such as a reduction in renal mass, renal blood flow, glomerular filtration rate, and tubular function, the ability of renal drug elimination can be declined (Hutchison and O'Brien, 2007). For renally excreted drugs, ageing causes changes in the pharmacokinetics of drugs leading to unexpected drug efficacy and safety (Tieu et al., 2016). Age-related alterations in liver function may also change drug metabolism and disposition through alteration of the cytochrome P450 (CYP) enzymes and drug transporter activity (Eldesoky, 2007; Nolin et al., 2008; Klotz, 2009; Yeung et al., 2014). Because of multiple comorbid conditions, polypharmacy is also more common in ageing patients. Physiologic changes in drug metabolism and clearance in the elderly increase the risk of adverse drug reactions and drug-drug interactions in this patient group (Dagli and Sharma, 2014; American Geriatrics Society Beers Criteria ${ }^{\circledR}$ Update Expert Panel, 2019).

Cytochrome P450 3A (CYP3A), the most abundant isozyme in the liver and intestine (Blech et al., 2008), plays an important role in metabolizing several drugs and is commonly implicated in pharmacokinetic drug-drug interactions (Lynch and Price, 2007). For the past decade, increasing numbers of clinically important drug-drug interactions mediated by drug transporters, including intestinal P-glycoprotein (intestinal P-gp), organic aniontransporting polypeptide $1 \mathrm{~B}$ (OATP1B), and breast cancer resistance protein (BCRP), have been reported (Giacomini et al., 2010).

Clinical studies using probe substrate cocktails are recognized by both the United States Food and Drug Administration (United States FDA) and the European Medicines Agency (EMA) to evaluate the activity of multiple CYP enzymes and drug transporters simultaneously (European Medicines Agency, 2012; Center for Drug Evaluation and Research (CDER) U.S. Department of Health and Human Sciences Food and Drug Administration, 2020). A cocktail comprising a sub-therapeutic dose (microdose) of 5 drugs was recently validated in healthy subjects (Prueksaritanont et al., 2017). The cocktail drugs include 1) midazolam (MDZ), a specific and selective substrate for CYP3A; 2) dabigatran etexilate (DABE), a selective substrate for intestinal P-gp; 3 ) pitavastatin (PTV), a relatively selective substrate for OATP1B; 4) rosuvastatin (RSV), a substrate of BCRP and OATP1B; and 5) atorvastatin (ATV), a substrate of CYP3A, OATP1B, BCRP, and $\mathrm{P}$-gp. This cocktail was subsequently studied in patients with $\mathrm{CKD}$, and the study results suggested that CKD reduces intestinal P-gp and BCRP activity (Tatosian et al., 2020). However, whether the observed changes were due solely to $\mathrm{CKD}$ or as a consequence of advancing age, remains inconclusive.

This study aimed to evaluate age- versus CKD-related changes in the activity of CYP3A and the drug transporters, P-gp, OATP, and BCRP, using a microdose cocktail in the elderly with and without CKD compared to young healthy participants.

\section{MATERIALS AND METHODS}

This study was a clinical pharmacokinetic study (Clinical trial registration number: TCTR 20180312002 registered on March 07, 2018). The study was approved by the Institutional Review Board of the Faculty of Medicine, Chulalongkorn University, Bangkok, Thailand, and was conducted in accordance with the Declaration of Helsinki and Good Clinical Practice Guidelines. Written informed consent was obtained from all participants before the start of the study. The nomenclature of enzymes and drug transporters conformed to the International Union of Basic and Clinical Pharmacology/British Pharmacological Society (IUPHAR/BPS) Guide to Pharmacology Nomenclature Classification (Alexander et al., 2017).

\section{Participants}

Participants were classified into three groups; group 1 (healthy young participants) aged 20-40 years with 


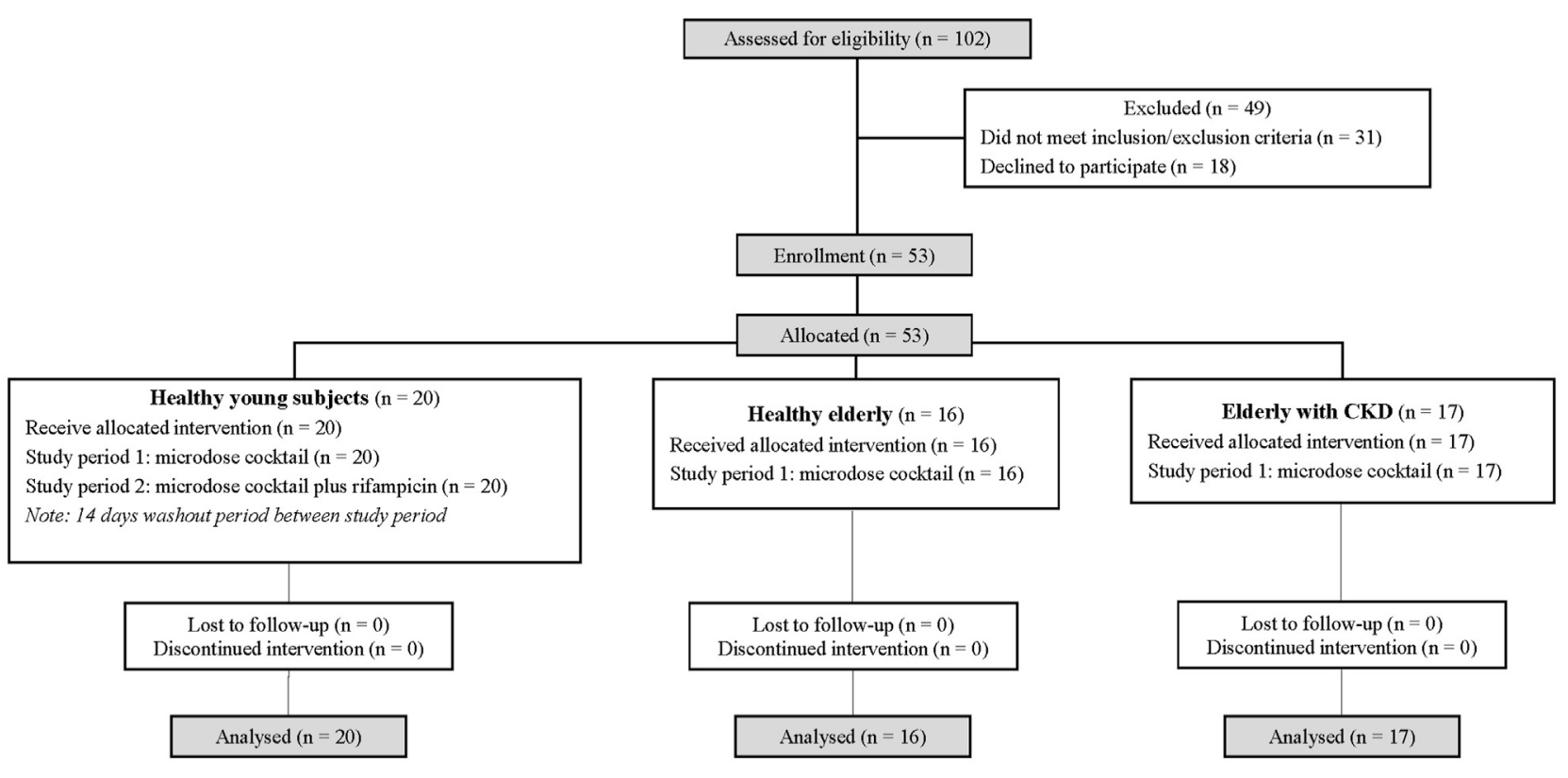

FIGURE 1 | Study flow diagram.

estimated glomerular filtration rate (eGFR) $\geq 90 \mathrm{ml} / \mathrm{min} /$ $1.73 \mathrm{~m}^{2}$, group 2 (healthy elderly participants) aged $\geq 60$ years with eGFR $>60 \mathrm{ml} / \mathrm{min} / 1.73 \mathrm{~m}^{2}$, and group 3 (elderly patients with CKD) aged $\geq 60$ years with eGFR $15-60 \mathrm{ml} / \mathrm{min} / 1.73 \mathrm{~m}^{2}$, diagnosed as patients with CKD by attending nephrologists. The pre-specified inclusion/ exclusion criteria were fully described in Supplementary Table S1. Modification of Diet in Renal Disease (MDRD) eGFR for Thai was calculated according to Praditpornsilpa et al. (2011).

We assumed that the area under the plasma concentration-time curve (AUC) of MDZ between healthy young participants and the elderly participants would differ by $70 \%$ with a common standard deviation of 11.84 , based on a previous study using the same microdose cocktail (Prueksaritanont et al., 2017). Under these assumptions, eleven participants per study group would give $90 \%$ power to detect these differences at a 2-sided significance level of $5 \%$. Therefore, a total of fifty-three participants was enrolled. Twenty, sixteen, and seventeen participants were healthy young adults, healthy elderly, and elderly patients with CKD, respectively (Figure 1).

Healthy young participants were recruited from the volunteers' database of Maha Chakri Sirindhorn Clinical Research Center under the Royal Patronage, Faculty of Medicine, Chulalongkorn University, Bangkok, Thailand. Healthy elderly participants were recruited from outpatients of the Comprehensive Geriatric Clinic, King Chulalongkorn Memorial Hospital, Thai Red Cross Society, Bangkok, Thailand. Elderly patients with CKD were recruited from an out-patient of the Nephrology Clinic, King
Chulalongkorn Memorial Hospital, by nephrologists in the study team.

\section{Clinical Study and Biological Sample Collection Procedures}

All participants were advised to refrain from xanthine-containing beverages, citrus juice, herbal and dietary supplements, and products containing St. John's wort for $72 \mathrm{~h}$ before study start, until study conclusion. In addition, healthy young and healthy elderly participants abstained from any drug intake for at least two weeks before the study date. Elderly patients with CKD continued their medications as usual, except for PTV, ATV, or RSV, which were stopped or switched to the equivalent dose of simvastatin at least two weeks before the study date. The concomitant drugs in elderly patients with CKD were also examined for potential drug-drug interaction with probe substrates in the microdose cocktail.

The powder formulation of microdose cocktail containing $30 \mu \mathrm{g}$ of $\mathrm{MDZ}, 750 \mu \mathrm{g}$ of DABE, $10 \mu \mathrm{g}$ of PTV, $100 \mu \mathrm{g}$ of $\mathrm{ATV}$, and $50 \mu \mathrm{g}$ of RSV, was prepared by a single pharmacist trained in the study procedures at the Pharmacy Department, King Chulalongkorn Memorial Hospital. The microdose cocktail was dissolved with $10 \mathrm{ml}$ of water into a solution before immediate oral administration.

All participants received a single oral dose of the microdose cocktail after $10 \mathrm{~h}$ of an overnight fast (study period 1). Venous blood samples were collected into EDTA tubes at predose (0) and $0.33,0.67,1,1.5,2,3,4,6,8,10,12,24,36$, and $48 \mathrm{~h}$ post-dose. Urine samples were collected at predose (0) and then between 0-4 h, 4-8 h, 8-12 h, 12-24 h, 24-36 h, and 36-48 h post-dose. 
Plasma and urine samples were aliquoted and kept at $-80^{\circ} \mathrm{C}$ until analysis. Samples for statins analysis were treated immediately with $1 \mathrm{M}$ ammonium buffer ( $\mathrm{pH}$ ) at a ratio of 5/100 (buffer/ plasma) to prevent interconversion. All participants stayed at the clinical study site for at least $12 \mathrm{~h}$ post-dose and returned for subsequent blood sample collections.

After a 2-week wash-out period, the healthy young participants continued to study period 2. On this occasion, participants received another single oral microdose cocktail together with $450 \mathrm{mg}$ of rifampicin (RIF), a well-known OATP1B, BCRP, and intestinal P-gp inhibitor, to evaluate the magnitude of drug-drug interactions between RIF and microdose cocktail in Thai subjects, as compared to the earlier study in Caucasian (Prueksaritanont et al., 2017). Blood and urine samples on study period 2 were collected as previously described in study period 1. The occurrence of any adverse event was carefully monitored throughout the study.

It has to be noted that during the final part of the study period, the MDZ tablet was not available in Thailand. Hence, an intravenous form of MDZ was used in 4 elderly patients with CKD instead. After dehydrating, the solution was prepared to power for the preparation of the microdose cocktail. Despite limited power, pharmacokinetic parameters between powder and solution of MDZ were similar (Supplementary Table S2).

\section{Bioanalysis}

Plasma concentrations of MDZ, dabigatran (DABI) which is an active metabolite of DABE (Blech et al., 2008), PTV, pitavastatin lactone (PTV-lactone), ATV, 2-hydroxy atorvastatin (2-OHATV), 4-hydroxy atorvastatin (4-OH-ATV), RSV, RIF, and stable isotope-labeled internal standards were quantified by a validated liquid chromatography-tandem mass spectrometry assay as previously described (Prueksaritanont et al., 2017). In addition, urine concentrations of DABI and RSV were also measured.

MDZ, statins, and RIF were measured using reverse-phase liquid chromatography. Hydrophilic interaction liquid chromatography with tandem mass spectrometric detection employing a turbo ion spray interface in positive ion mode was used for DABI. The lower limit of quantitation (LLOQ) was $1 \mathrm{pg} / \mathrm{ml}$ for $\mathrm{MDZ}, 20 \mathrm{pg} / \mathrm{ml}$ for $\mathrm{DABI}$, and $5 \mathrm{pg} / \mathrm{ml}$ for statins and their metabolites.

\section{Genotype Analysis}

The Clinical Pharmacogenetics Implementation Consortium (CPIC) guideline recommends simvastatin drug monitoring and dose adjustment in patients based on solute carrier organic anion transporter 1B1 (SLCO1B1) genotypic test results, as statins levels are affected by single nucleotide polymorphisms (SNPs) in drug transporters (Ramsey et al., 2014). Therefore, we genotyped participants for SLCO1B1 and ATP Binding Cassette Subfamily G2 (ABCG2) genes to adjust for this possible confounding factor (Keskitalo et al., 2009; Romaine et al., 2010; Ramsey et al., 2014). The genotyping methods together with the genetic variation in SLCO1B1 c.521T > C (rs4149056), c.388A > G (rs2306283), g.-11187G > A (rs4149015), and ABCG2 c.421C > A (rs2231142) of all study participants have previously been reported (Rattanacheeworn et al., 2020). In addition, as genetic variation in CYP3A was reported in the Thai population (Mauleekoonphairoj et al., 2020), genotyping for $C Y P 3 A 5^{\star} 3$ c.6986A > G (rs776746) was also carried out in all participants. Supplementary Table S3 summarized the distribution and the genotyping method of $C Y P 3 A 5^{\star} 3$ in this study.

\section{Pharmacokinetic Analysis}

Pharmacokinetic data were analyzed using noncompartmental methods. Maximum plasma concentration $\left(\mathrm{C}_{\max }\right)$ and time to maximum plasma concentration $\left(\mathrm{T}_{\max }\right)$ were directly obtained from the individual plasma drug concentration profiles versus the time curve. The area under the plasma concentration-time curve from time zero to the last point with measurable concentration $\left(\mathrm{AUC}_{0 \text {-last }}\right)$ was calculated using the log-linear trapezoidal rule. $\mathrm{AUC}_{0 \text {-inf }}$ was obtained from the summation of $\mathrm{AUC}_{0 \text {-last }}$ and the last observed quantifiable concentration $\left(\mathrm{C}_{\text {last }}\right)$ /elimination rate constant $\left(\mathrm{K}_{\mathrm{el}}\right) . \mathrm{K}_{\mathrm{el}}$ was estimated by log-linear least square regression of the terminal part of the plasma concentration versus time curve. Half-life $\left(\mathrm{T}_{1 / 2}\right)$ was calculated using a natural logarithm of $2(\ln 2)$ divided by $\mathrm{K}_{\mathrm{el}}$. Oral clearance $(\mathrm{CL} / \mathrm{F}$ with weight normalization) was also calculated as dose divided by $\mathrm{AUC}_{0 \text {-last }}$. The cumulative amount in urine $\left(\mathrm{A}_{\mathrm{e}}\right)$ was measured and divided by $\mathrm{AUC}_{0 \text {-last }}$ to estimate renal clearance $\left(\mathrm{CL}_{\mathrm{R}}\right)$ in $\mathrm{DABI}$ and $\mathrm{RSV}$. Additionally, the theoretical $\mathrm{AUC}_{0 \text {-last }}$ ratios (AUCR) in $\mathrm{AUC}_{0 \text {-last }}$ of healthy elderly and elderly patients with $\mathrm{CKD}$ over $\mathrm{AUC}_{0 \text {-last }}$ of healthy young participants were calculated for DABI and RSV, assuming no change in bioavailability (F). The calculated AUCRs were compared to the observed AUCRs to confirm the effects of ageing and/or CKD on intestinal P-gp and BCRP functions.

\section{Statistical Analysis}

Statistical analysis was performed with STATA version 15.0 (Stata Corp, College Station, TX, United States). Graphs were created by GraphPad Prism version 8.0 (GraphPad Software, Inc., San Diego, CA, United States). Demographic data are presented as median (interquartile range; IQR) or frequency (\%) for continuous and categorical data, respectively. A Kruskal-Wallis test analyzed formal comparisons of continuous characteristics between groups, and when differences were found, pairwise comparisons were further investigated with a Wilcoxon ranksum test. Finally, categorical characteristics were compared with a Chi-square or Fisher's exact test as appropriate.

The geometric mean (GM) with 95\% confidence interval (95\%CI) was calculated for $\mathrm{AUC}_{0 \text {-last }}, \mathrm{AUC}_{0 \text {-inf }} \mathrm{C}_{\max }, \mathrm{CL} / \mathrm{F}$, and $\mathrm{CL}_{\mathrm{R}}$. Regression techniques with an outcome of the natural logarithm of each parameter were developed for these parameters, and pairwise comparisons were made between groups. The relevant model parameters were then exponentiated to obtain geometric mean ratios (GMR) and corresponding 95\% confidence interval $(95 \% \mathrm{CI}) . \mathrm{T}_{\max }$ and $\mathrm{T}_{1 / 2}$ were reported as median (IQR), and pairwise comparisons were made with a Kruskal-Wallis test/Wilcoxon test for demographic parameters. Pre-RIF versus post-RIF comparisons in healthy young participants were assessed using Generalized Estimating Equation (GEE). All $p$-values were adjusted for multiple comparisons using a Bonferroni correction. Multivariable models were used to adjust group differences for potential confounders, including gender, body weight, alanine aminotransferase, aspartate aminotransferase, total bilirubin, direct bilirubin, albumin, and genotype of SLCO1B1 and ABCG2 genes. 
TABLE 1 | Baseline characteristics.

\begin{tabular}{|c|c|c|c|c|c|c|}
\hline Parameters & $\begin{array}{c}\text { Healthy young } \\
\text { adults }\end{array}$ & Healthy elderly & $\begin{array}{l}\text { Healthy young } \\
\text { adults vs. } \\
\text { healthy elderly }\end{array}$ & $\begin{array}{c}\text { Elderly with } \\
\text { CKD }\end{array}$ & $\begin{array}{l}\text { Healthy young } \\
\text { adults vs. } \\
\text { elderly with } \\
\text { CKD }\end{array}$ & $\begin{array}{c}\text { Healthy elderly } \\
\text { vs. elderly } \\
\text { patients with } \\
\text { CKD }\end{array}$ \\
\hline $\mathrm{N}$ & 20 & 16 & & 17 & & \\
\hline Male/female $(n / n)$ & $8 / 12$ & $4 / 12$ & & $13 / 4$ & & \\
\hline Age (year) & $30(28-32)$ & $65(62-67)$ & $p<0.001$ & $74(67-77)$ & $p<0.001$ & ns \\
\hline Body weight (kg) & $54.2(46.8-65.5)$ & $60.4(52.4-65.0)$ & ns & $66.5(60.8-70.3)$ & $p=0.0140$ & ns \\
\hline \multicolumn{7}{|l|}{ Biochemistry } \\
\hline Blood urea nitrogen (mg/dL) & $10(10-12)$ & $11(10-14)$ & ns & $26(21-37)$ & $p<0.001$ & $p<0.001$ \\
\hline Serum creatinine $(\mathrm{g} / \mathrm{dL})$ & $0.7(0.7-0.9)$ & $0.7(0.6-0.8)$ & ns & $2.2(1.8-2.9)$ & $p<0.001$ & $p<0.001$ \\
\hline eGFR $^{a}$ corrected by BSA (mL/min) & $112(106-118)$ & $95(86-110)$ & ns & $33(24-40)$ & $p<0.001$ & $p<0.001$ \\
\hline Parathyroid hormone (pg/mL) & $55(45-60)$ & $63(49-76)$ & ns & $113(76-168)$ & $p<0.001$ & $p<0.001$ \\
\hline Fasting plasma glucose (mg/dL) & $85(81-93)$ & $95(90-102)$ & ns & $98(88-105)$ & ns & ns \\
\hline Total protein $(\mathrm{g} / \mathrm{dL})$ & $7.8(7.5-7.9)$ & $7.7(7.3-7.8)$ & ns & $7.6(7.1-7.7)$ & ns & ns \\
\hline Albumin (g/dL) & $4.5(4.3-4.6)$ & $4.3(4.3-4.5)$ & ns & $4.3(4.2-4.4)$ & ns & ns \\
\hline Total bilirubin (mg/dL) & $0.6(0.5-0.8)$ & $0.6(0.6-0.9)$ & ns & $0.6(0.5-0.7)$ & ns & ns \\
\hline Direct bilirubin (mg/dL) & $0.2(0.2-0.4)$ & $0.3(0.2-0.3)$ & ns & $0.3(0.2-0.3)$ & ns & ns \\
\hline Aspartate aminotransferase (U/L) & $16(15-20)$ & $22(19-24)$ & ns & $18(16-26)$ & ns & ns \\
\hline Alanine aminotransferase (U/L) & $15(13-20)$ & 19 (16-22) & ns & $19(16-25)$ & ns & ns \\
\hline Alkaline phosphatase (U/L) & $54(47-66)$ & $67(56-75)$ & ns & $64(53-73)$ & ns & ns \\
\hline Total cholesterol (mg/dL) & $203(176-225)$ & $242(209-270)$ & ns & $167(152-177)$ & ns & ns \\
\hline Triglyceride (mg/dL) & $87(61-107)$ & $130(94-191)$ & ns & $91(87-141)$ & ns & ns \\
\hline \multicolumn{7}{|l|}{ Co-morbidity } \\
\hline Hypertension & - & - & & $14(82)$ & & \\
\hline Dyslipidemia & - & - & & $11(65)$ & & \\
\hline Diabetes Mellitus & - & - & & $11(65)$ & & \\
\hline Coronary heart disease & - & - & & $1(6)$ & & \\
\hline Chronic kidney disease & - & - & & $17(100)$ & & \\
\hline Osteoarthritis & - & $2(13)$ & & $1(6)$ & & \\
\hline Benign prostatic hypertrophy & - & $1(6)$ & & $1(6)$ & & \\
\hline Gout & - & $1(6)$ & & $1(6)$ & & \\
\hline
\end{tabular}

Data are presented in the median (interquartile range) unless otherwise stated. CKD: chronic kidney disease; eGFR: estimated glomerular filtration rate; BSA: body surface area; ns: nonsignificant.

a Modification of Diet in Renal Disease estimated glomerular filtration rate for Thai formula (Praditpornsilpa et al., 2011).

\section{RESULTS}

\section{Baseline Characteristics}

Baseline characteristics between three groups of participants were comparable except for age, body weight, and renal function (Table 1). The median age was 30,65 , and 74 years and the median eGFR corrected for body surface area (BSA) was 112, 95, and $33 \mathrm{ml} / \mathrm{min}$ for healthy young participants, healthy elderly, and elderly patients with CKD, respectively (Table 1). From a list of concomitant drugs in elderly patients with CKD (Supplementary Table S4), no potential pharmacokinetic drug-drug interaction to probe substrates used in this study was noted.

\section{Pharmacokinetic Parameters of Probe Substrates Midazolam}

$\mathrm{AUC}_{0 \text {-last, }} \mathrm{AUC}_{0 \text {-inf, }}$ and $\mathrm{C}_{\max }$ of $\mathrm{MDZ}$ were significantly increased in healthy elderly $(2.30,2.32$, and 1.88 fold, respectively) and elderly patients with $\operatorname{CKD}(2.90,2.90$, and 1.95 fold, respectively), as compared to healthy young adults.
$\mathrm{T}_{1 / 2}$ was also prolonged in healthy elderly and elderly patients with CKD. No significant differences were seen between the groups of healthy elderly and elderly patients with CKD (Table 2; Figure 2A). As anticipated and previously shown by Prueksaritanont et al. (2017), RIF showed no effect on the pharmacokinetics of MDZ (Table 2).

\section{Dabigatran}

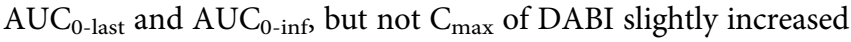
with ageing (1.55, 1.46, and 1.27 fold, respectively), while elderly patients with $\mathrm{CKD}$ showed a marked increase in drug exposure $\left(\mathrm{AUC}_{0 \text {-last }} 4.11\right.$ fold, $\mathrm{AUC}_{0 \text {-inf }} 4.26$ fold, and $\mathrm{C}_{\max } 1.70$ fold) when compared to healthy young controls. Elderly patients with $\mathrm{CKD}$ had higher $\mathrm{AUC}_{0 \text {-last }}$ and $\mathrm{AUC}_{0 \text {-inf }}$ than healthy elderly (GMR (95\% CI): 2.65 (1.91-3.69) and 2.91 (2.14-3.95), respectively), but no differences were observed in $\mathrm{C}_{\text {max }}$. The theoretical AUCR of DABI was increased with the same magnitude, as seen in the observed AUCRs in healthy elderly (1.70 fold) but not for elderly patients with CKD (2.84 fold). Of note, both healthy elderly and elderly patients with CKD had a reduction in $\mathrm{DABI} \mathrm{CL}_{\mathrm{R}}$ by 40 and $80 \%$, respectively, but only the elderly patients with CKD had a very prolonged DABI $T_{1 / 2}(\sim 3$ fold, Table 2 and Figure $2 B)$. RIF 
TABLE 2 | Pharmacokinetic parameters of midazolam and dabigatran

Drugs

Healthy young adults

\begin{tabular}{|c|c|c|}
\hline \multirow{2}{*}{$\frac{\text { Microdose }}{\text { GM }}$} & \multicolumn{2}{|c|}{ Microdose + Rifampicin } \\
\hline & GM & GMR \\
\hline (95\%Cl) & $(95 \% \mathrm{Cl})$ & $(95 \% \mathrm{Cl})$ \\
\hline
\end{tabular}

\section{Midazolam}

$\mathrm{AUC}_{\text {O-last }}(\mathrm{pg}$

mL.hr)

$\mathrm{AUC}_{\mathrm{O}-\mathrm{inf}}(\mathrm{pg}$

$\mathrm{mL} . \mathrm{hr}$ )

$\mathrm{C}_{\max }(\mathrm{pg} / \mathrm{mL})$

$\mathrm{T}_{\text {max }}(\mathrm{hr})^{\mathrm{a}}$

$\mathrm{T}_{1 / 2}(\mathrm{hr})^{\mathrm{a}}$

$\mathrm{CL} / \mathrm{F}(\mathrm{mL})$

$\mathrm{min} / \mathrm{kg}^{0.75}$ )

Dabigatran

$\mathrm{AUC}_{\text {O-last }}$ (pg/

$\mathrm{mL} . \mathrm{hr})$

$\mathrm{AUC}_{\mathrm{O}-\text { inf }}(\mathrm{pg} /$

$\mathrm{mL} . \mathrm{hr})$

$\mathrm{C}_{\max }(\mathrm{pg} / \mathrm{mL})$

$\mathrm{T}_{\text {max }}(\mathrm{hr})^{\mathrm{a}}$

$\mathrm{T}_{1 / 2}(\mathrm{hr})^{\mathrm{a}}$

CL/F (mL/

$\mathrm{min} / \mathrm{kg}^{0.75}$ )

$\mathrm{CL}_{\mathrm{R}}, \mathrm{mL} / \mathrm{min}$
192 (155-237)

200 (162-247)

80 (67-96)

$0.7(0.7-0.7)$

$2.7(2.1-3.4)$

2,661

(2,147-3,298)

3,111

(2,577-3,757)

375 (302-467)

$1.5(1.0-1.5)$

$6.6(4.6-7.8)$

228 (190-274)

78 (70-88)
127 (105-152)

\section{8 (198-309)}

$256(206-318)$

78 (96-118)

$0.7(0.7-0.8)$

2.5 (1.8-3.0)

98 (81-118)

6,228

$(5,165-7,511)$

6,902

$(5,849-8,146)$

699 (593-824)

$2.0(2.0-2.5)^{\star}$

$7.4(5.8-10.6)$

97 (85-112)

59 (53-66)
$1.29(0.96-1.74)$

$1.28(0.96-1.72)$

$1.20(0.92-1.56)$

$-$

$.77(0.60-1.00)$

$2.34(1.78-3.08)^{\star}$

$2.22(1.74-2.83)^{\star}$

$1.86(1.43-2.43)^{\star}$

$-$

$0.43(0.34-0.53)^{\star}$

$0.76(0.65-0.88)^{*}$

\begin{tabular}{cc}
\multicolumn{2}{c}{ Healthy elderly } \\
\hline \multicolumn{2}{c}{ Microdose } \\
\hline $\begin{array}{c}\text { GM } \\
(95 \% \mathrm{Cl})\end{array}$ & GMR \\
\end{tabular}

Elderly patients with chronic kidney disease

\begin{tabular}{cc}
\hline \multicolumn{3}{c}{ Microdose } \\
\hline GM & GMR \\
$(95 \% \mathrm{Cl})$ & $(95 \% \mathrm{Cl})$
\end{tabular}

$440(342-567) \quad 2.30(1.70-3.09)^{*}$

$556(454-681)$

$2.90(2.16-3.88)^{\star}$

$464(365-590) \quad 2.32(1.74-3.10)^{*}$

579 (475-705)

$2.90(2.18-3.85)^{\star}$

$151(119-191) \quad 1.88(1.44-2.44)^{\star}$

$0.7(0.7-1.0)$

$5.9(4.0-7.7)^{\star}$

$53(42-67)$

$.88(1.44$

$156(132-185)$

$0.7(0.7-1.0)$

$7.3(5.3-8.1)^{\star}$

$0.42(0.32-0.55)^{*} \quad 39(32-47)$

$1.95(1.51-2.52)^{*}$

$-$

$0.31(0.23-0.40)^{\star, 9}$

4,118

$(3,136-5,408)$

4,557

(3,554-5,844)

477 (378-601)

$1.5(1.0-1.5)$

$6.9(5.9-8.2)$

141 (109-184)

$1.55(1.13-2.12)^{\star}$

10,930

(8,714-13,708)

13,242

$1.46(1.09-1.97)^{\star}$

$(10,480-16,732)$

$1.27(0.94-1.73)$

640 (506-808)

$1.5(1.0-2.0)$

$16.8(14.5-21.7)^{\star, \text { ๆ }}$

49 (40-61)

$4.11(3.01-5.61)^{\star, 9}$

$4.26(3.18-5.70)^{*, 9}$

$1.70(1.26-2.30)^{*}$

$-$

$0.62(0.47-0.83)^{\star}$

$49(40-61)$

$0.22(0.16-0.29)^{\star, ~ ๆ ~}$

48 (39-59)

$0.61(0.48-0.78)^{\star}$

$15(12-18)$

$0.19(0.15-0.24)^{\star, 9}$

${ }^{a}$ Data are presented in the median (interquartile range).

*p-value $<0.05$, healthy young adult as a reference group.

$"$ p-value $<0.05$, healthy elderly as a reference group.

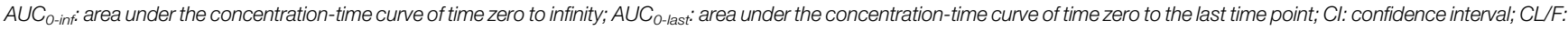
oral clearance; $C L_{R}$ : renal clearance; $C_{\text {max }}$ : maximum plasma concentration; GM: geometric mean; GMR: geometric mean ratio; $T_{\text {max: }}$ time to maximum plasma concentration; $T_{1 / 2}$ : halflife.

significantly increased $\mathrm{AUC}_{0 \text {-last }}, \mathrm{AUC}_{0 \text {-inf }}$, and $\mathrm{C}_{\max }$ of DABI but reduced $\mathrm{CL}_{\mathrm{R}}$ of DABI by $25 \%$ (Table 2 ).

\section{Pitavastatin and Pitavastatin Lactone}

Only elderly patients with $\mathrm{CKD}$ showed a significant increase in

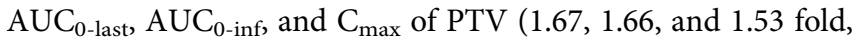
respectively) and PTV-lactone (1.81, 1.87, and 1.35 fold, respectively), as compared to healthy young adults (Table 3; Figures 2C,D). On the other hand, the $\mathrm{AUC}_{0 \text {-last }}$ ratios for PTVlactone/PTV were similar in all groups of participants (Table 3). RIF markedly increased $\mathrm{AUC}_{0 \text {-last }}, \mathrm{AUC}_{0 \text {-inf, }}$ and $\mathrm{C}_{\max }$ of PTV, but lesser effects were observed with PTV-lactone, resulting in a significant decrease in the $\mathrm{AUC}_{0 \text {-last }}$ ratios for PTV-lactone/PTV ratio when RIF was administered (Table 3 ).

\section{Atorvastatin and 4-Hydroxy Atorvastatin}

AUC $_{0 \text {-last }}$ and $\mathrm{C}_{\max }$ of both ATV and 4-OH-ATV were increased in healthy elderly (2.14 and 2.22 fold, respectively, for ATV; 1.55 and 1.27 fold, respectively, for 4-OH-ATV) and more prominently increased in elderly patients with CKD (4.15 and 4.18 fold, respectively, for ATV; 2.58 and 1.84 fold, respectively, for 4-OH-ATV) as compared to healthy young participants (Table 4; Figures 2E,F). The $\mathrm{AUC}_{0 \text {-last }}$ ratios for 4-OH-ATV/ATV were also reduced by approximately $20-30 \%$ in healthy elderly and elderly patients with $\mathrm{CKD}$, compared to healthy adults (Table 4). RIF resulted in a marked increase in $A C_{0 \text {-last }}$ and $C_{\max }$ of ATV and 4-OH-ATV, but no changes were observed in the $\mathrm{AUC}_{0 \text {-last }}$ ratio for 4-OH-ATV/ATV (Table 4). Unfortunately, pharmacokinetic parameters of 2-OH-ATV could not be estimated as the plasma 2-OH-ATV concentrations were lower than the assay's LLOQ.

\section{Rosuvastatin}

Elderly patients with $\mathrm{CKD}$ showed increased $\mathrm{AUC}_{0 \text {-last }}(1.90 \mathrm{fold})$ and $\mathrm{C}_{\max }(1.63$ fold) of RSV when compared to healthy young controls (Table 4; Figure 2G). The theoretical AUCRs of RSV were 1.19 fold in healthy elderly and 1.32 fold in elderly patients with $\mathrm{CKD}$, compared to healthy young participants. $\mathrm{CL}_{\mathrm{R}}$ of RSV was considerably low in elderly patients with CKD (80\% reduction) compared to healthy elderly (30\% reduction, Table 4). As previously observed (Prueksaritanont et al., 2017), $\mathrm{AUC}_{0 \text {-last }}$ and $\mathrm{C}_{\max }$ of RSV were increased with RIF (Table 4).

\section{Multivariate Analysis}

Multivariate analyses for each drug in the microdose cocktail were carried out, adjusting for factors known to influence pharmacokinetic parameters. The results confirmed that all significant differences seen in the univariate analysis were independent of confounders (Table 5). 

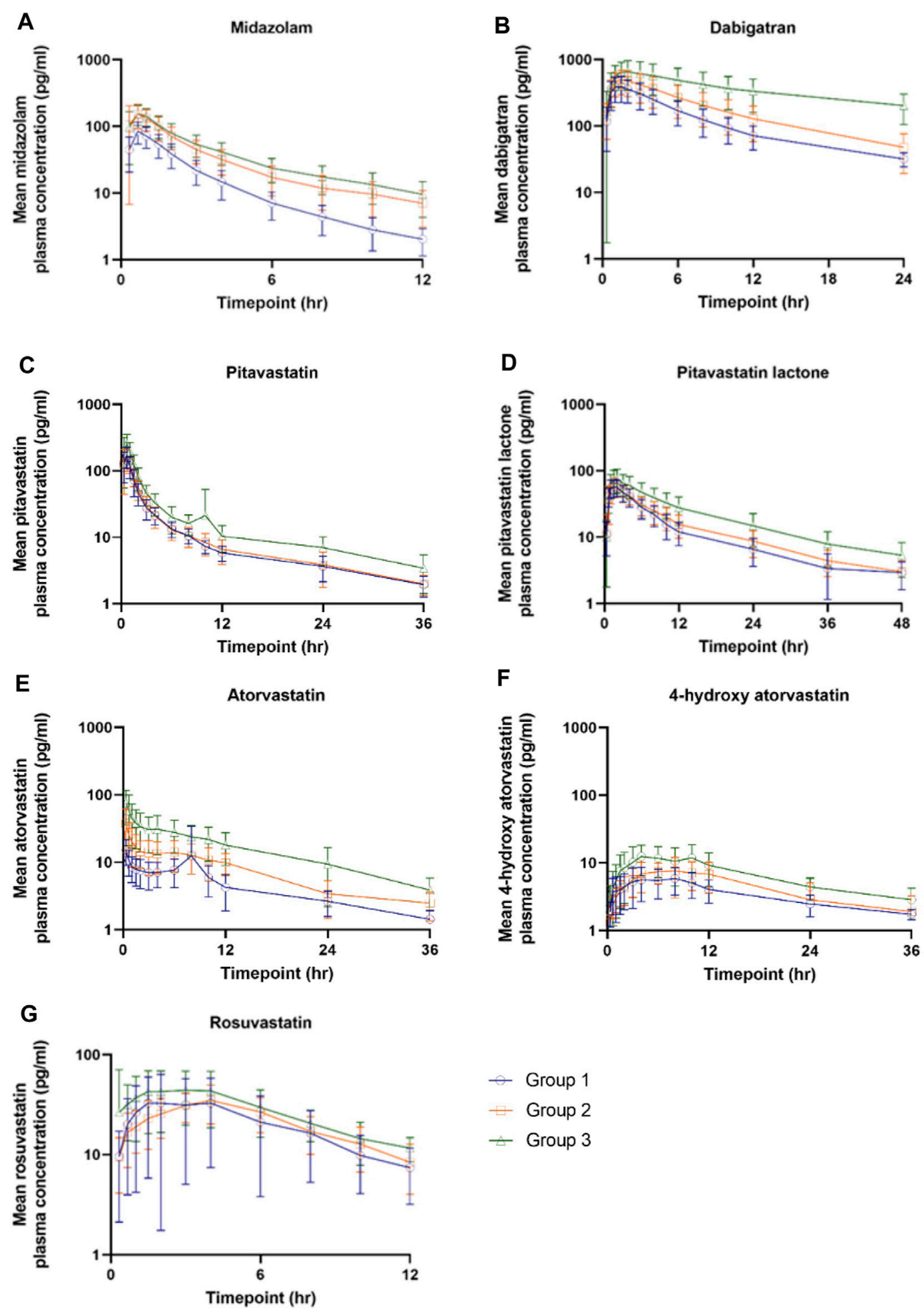

FIGURE 2 | The plasma concentration-time curves of microdose cocktail probe substrates in three groups of participants (A) Midazolam (B) Dabigatran (C) Pitavastatin (D) Pitavastatin lactone (E) Atorvastatin (F) 4-hydroxy Atorvastatin, and (G) Rosuvastatin. Group 1: healthy young participants; Group 2: healthy elderly participants; Group 3: elderly patients with chronic kidney disease. 
TABLE 3 | Pharmacokinetic parameters of pitavastatin and pitavastatin lactone.

\begin{tabular}{cc}
\hline \multicolumn{2}{c}{ Microdose } \\
\hline GM & GMR \\
$(95 \% \mathrm{Cl})$ & $(95 \% \mathrm{Cl})$
\end{tabular}

Drugs

Healthy young adults

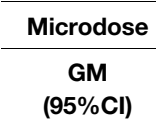

\begin{tabular}{cr}
\multicolumn{2}{c}{ Microdose + Rifampicin } \\
\hline GM & GMR \\
$(95 \% \mathrm{Cl})$ & $(95 \% \mathrm{Cl})$
\end{tabular}

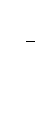

Healthy elderly

$(95 \%$

\section{Pitavastatin}

$\mathrm{AUC}_{\text {O-last }}(\mathrm{pg}$

$\mathrm{mL} . \mathrm{hr})$

$\mathrm{AUC}_{\mathrm{O}-\text { inf }}(\mathrm{pg} /$

$\mathrm{mL} . \mathrm{hr})$

$\mathrm{C}_{\max }(\mathrm{pg} / \mathrm{mL})$

$\mathrm{T}_{\max }(\mathrm{hr})^{\mathrm{a}}$

$\mathrm{T}_{1 / 2}(\mathrm{hr})^{\mathrm{a}}$

$\mathrm{CL} / \mathrm{F}(\mathrm{mL} /$

$\mathrm{min} / \mathrm{kg}^{0.75}$ )

Pitavastatin lactone

$\mathrm{AUC}_{\text {-last }}$ (pg/ 524 (440-623)

$\mathrm{mL} . \mathrm{hr})$

$\mathrm{AUC}_{\mathrm{O}-\text { inf }}(\mathrm{pg} /$

$\mathrm{mL} . \mathrm{hr})$

$\mathrm{C}_{\max }(\mathrm{pg} / \mathrm{mL})$

$\mathrm{T}_{\max }(\mathrm{hr})^{\mathrm{a}}$

$\mathrm{T}_{1 / 2}(\mathrm{hr})^{\mathrm{a}}$

Pitavastatin lactone/Pitavastatin ratio

$\mathrm{AUC}_{\mathrm{O} \text {-last }}$

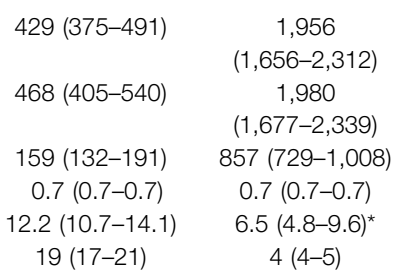

429 (375-491)

$468(405-540)$

$159(132-191)$

$0.7(0.7-0.7)$

$12.2(10.7-14.1)$

$19(17-21)$

1,956

(1,656-2,312)

1,980

(1,677-2,339)

$857(729-1,008)$

$0.7(0.7-0.7)$

$6.5(4.8-9.6)^{*}$

$4(4-5)$

574 (475-693)

$1.5(1.0-1.8)$

13.1 (8.6-17.6)

$1.22(1.08-1.38)$
$59(51-68)$

48 (58-69)
649 (556-759)

690 (589-809)

76 (67-86)

$1.5(1.0-2.0)$

$12.8(8.9-18.1)$

$0.33(0.30-0.37)$ $4.56(3.71-5.61)^{\star}$

446 (375-530)

$1.04(0.82-1.31)$

$4.24(3.42-5.24)^{*}$

$5.40(4.25-6.86)^{\star}$

$-$

$0.22(0.19-0.26)^{\star}$

$1.24(0.99-1.56)$

$1.20(0.95-1.53)$

$1.29(1.08-1.55)^{\star}$

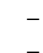

$-$

$0.40(0.34-0.47)^{\star}$
494 (417-585)

1.06 (0.83-1.34)

154 (123-192)

$0.7(0.7-0.7)$

$12.6(11.4-15.9)$

17 (15-20)

604 (494-739)

676 (558-819)

$1.5(1.5-1.5)$

$13.7(11.6-17.9)$

$0.97(0.73-1.28)$

$0.7(0.7-0.7)$

$15.0(11.3-17.6)$

$10(8-12)$

$0.92(0.74-1.13)$

$1.15(0.89-1.50)$

$1.18(0.90-1.54)$

$0.98(0.78-1.22)$

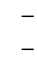

-

$1.35(1.22-1.51)$
Elderly patients with chronic kidney disease

\begin{tabular}{cc}
\multicolumn{3}{c}{ Microdose } \\
\hline GM & GMR \\
$(95 \% \mathrm{Cl})$ & $(95 \% \mathrm{Cl})$
\end{tabular}

$15(578-885) \quad 1.67(1.33-2.09)^{*}$, "

$74(624-959) \quad 1.66(1.32-2.08)^{\star, 9}$

${ }^{a}$ Data are presented in the median (interquartile range).

${ }^{*} \mathrm{p}$-value $<0.05$, healthy young adult as a reference group.

"p-value $<0.05$, healthy elderly as a reference group.

$A \cup C_{O-\text { inf: }}$ area under the concentration-time curve of time zero to infinity; AUC $\mathrm{O}_{\text {-last: }}$ area under the concentration-time curve of time zero to the last time point; CL/F: oral clearance; Cl: confidence interval; $C_{\text {max: }}$ maximum plasma concentration; GM: geometric mean; GMR: geometric mean ratio; $T_{\text {max }}$ : time to maximum plasma concentration; $T_{1 / 2}$ : half-life.

\section{Effects of Genetic Variations on the Pharmacokinetics of Statins and \\ Midazolam}

The genetic variations of the SLCO1B1 gene did not affect the pharmacokinetics of statins used in this study. In contrast, participants with ABCG2 variants (421AA and 421CA genotypes, $n=24$ ) showed increased $\mathrm{AUC}_{0 \text {-last }}$ and $\mathrm{C}_{\max }$ of RSV than $A B C G 2$ wild type (Supplementary Table S5). Therefore, the participants with genotype variants (421AA and 421CA) were excluded from the multivariate model in a sensitivity analysis. The results showed that $\mathrm{AUC}_{0 \text {-last }}$ and $\mathrm{C}_{\max }$ of RSV in the elderly patients with $\mathrm{CKD}$ and $\mathrm{AUC}_{0}$ last in healthy elderly were higher than those corresponding values in the healthy young participants (Table 4 and Supplementary Figure S1).

Due to the non-significant correlation of CYP3A genetic variation with $\mathrm{MDZ}$ pharmacokinetics as reported in previous studies (He et al., 2005; Miao et al., 2009; Singh et al., 2009), $C Y P 3 A 5^{*} 3$ genetic variation was not included in multivariate analysis. Supplementary Table S3 showed the genotype frequency of $C Y P 3 A 5^{*}$. Pharmacokinetics of $\mathrm{MDZ}$ in wild-type CYP3A5 showed an increase in $\mathrm{AUC}_{0 \text {-last }}$ (2.53 fold), $\mathrm{AUC}_{0 \text {-inf }}$ (2.57 fold), and $\mathrm{C}_{\max }(1.83$ fold) in elderly patients with $\mathrm{CKD}$ as compared to healthy young participants (Supplementary Table S6). Pharmacokinetics profiles of MDZ between CPY3A5 genetic variants (6968AG and 6986GG) and wild type (6986AA) were also compared in healthy young participants. There were no differences observed between them (Supplementary Table S7).

\section{Safety}

Mild adverse events including diarrhea, dysmenorrhea, dyspepsia, migraine, and nasal congestion were observed in six participants. These adverse events were unrelated to the drugs listed in the microdose cocktail. In study period 2, healthy young participants had darkened urine as a result of RIF administration. Additionally, there were no significant changes in the physical examination and clinical laboratory parameters between baseline and the end of study (Supplementary Table S8).

\section{DISCUSSION}

Our study investigated the activity of CYP3A and drug transporters in three participant groups using a validated microdose cocktail containing five probe substrates, with no inhibitor activity of any enzymes and/or transporters (U.S. Food and Drug Administration, 2020). We found that CYP3A and intestinal P-gp activities are reduced in ageing and CKD, respectively. There is a trend of changes in OATP1B and BCRP activity measured by microdose cocktail probe drugs.

The probe substrates in the drug cocktail should be specific and devoid of any drug-drug interactions to allow precise quantification of enzymes or activity of drug transporters (Fuhr et al., 2019). Our microdose cocktail had specificity (MDZ) and relative selectivity (DABE and PTV). The 
TABLE 4 | Pharmacokinetic parameters of atorvastatin, 4-hydroxy atorvastatin, rosuvastatin, and rosuvastatin with ABCG2 gene wild-type (rs2231142).

Drugs

Healthy young adults

\begin{tabular}{|c|c|c|}
\hline Microdose & Micro & fampicin \\
\hline $\begin{array}{c}\text { GM } \\
(95 \% \mathrm{Cl})\end{array}$ & $\begin{array}{c}\text { GM } \\
(95 \% \mathrm{Cl})\end{array}$ & $\begin{array}{c}\text { GMR } \\
(95 \% \mathrm{Cl})\end{array}$ \\
\hline
\end{tabular}

\section{Atorvastatin}

$\mathrm{AUC}_{\text {O-last }}(\mathrm{pg}$

$\mathrm{mL} . \mathrm{hr}$ )

$\mathrm{C}_{\max }(\mathrm{pg} / \mathrm{mL})$

$\mathrm{T}_{\max }(\mathrm{hr})^{\mathrm{a}}$

$\mathrm{CL} / \mathrm{F}(\mathrm{mL} /$

$\mathrm{min} / \mathrm{kg}^{0.75}$ )

4-Hydroxy atorvastatin

$\mathrm{AUC}_{\mathrm{O}-\mathrm{last}}(\mathrm{pg}$

$\mathrm{mL} . \mathrm{hr})$

$\mathrm{C}_{\max }(\mathrm{pg} / \mathrm{mL})$

$\mathrm{T}_{\max }(\mathrm{hr})^{\mathrm{a}}$

4-Hydroxy

$131(102-168)$

767 (609-965)

$5.84(4.21-8.10)^{*}$

$16(12-21)$

$0.3(0.3-0.3)$

617 (479-793)

258 (196-339)

$0.7(0.7-1.0)^{\star}$

$16.37(11.25-23.81)^{*}$

$-$

$106(88-126)$

$0.17(0.13-0.23)^{\star}$

94 (74-120)

729 (590-901)

$7.75(5.67-10.58)^{\star}$

$\begin{array}{cc}7(6-8) & 109(89-134) \\ 5.0(4.0-8.0) & 2.0(1.0-2.5)^{*}\end{array}$

$16.08(12.40-20.86)^{\star}$

$-$

$\mathrm{AUC}_{0 \text {-last }}$

$0.72(0.57-0.90)$

0.95

(0.84-1.07)

$1.20(0.96-1.50)$

851

$\mathrm{AUC}_{0} \mathrm{pg} /$

$\mathrm{mL} . \mathrm{hr}$ )

$\mathrm{C}_{\max }(\mathrm{pg} / \mathrm{mL})$

$\mathrm{T}_{\max }(\mathrm{hr})^{\mathrm{a}}$

CL/F (mL/

$\mathrm{min} / \mathrm{kg}^{0.75}$ )

$\mathrm{CL}_{\mathrm{R}}(\mathrm{mL} / \mathrm{min})$

Rosuvastatin with ABCG2 gene wild-type (rs2231142)

$\mathrm{AUC}_{0 \text {-last }}(\mathrm{pg} /$

$\mathrm{mL} . \mathrm{hr}$ )

$\mathrm{C}_{\max }(\mathrm{pg} / \mathrm{mL})$

700 (570-860)

$25(17-37)$

$203(143-290)$

$232(177-305)$

$1.0(1.0-1.5)^{\star}$

$48(39-57)$

$4.35(2.84-6.67)^{\star}$

$7.21(4.78-10.89)^{\star}$

$-$

$0.23(0.15-0.34)^{\star}$

$0.66(0.55-0.79)^{\star}$

$5.15(3.36-7.89)^{*}$

$8.04(4.87-13.28)^{\star}$

Elderly patients with chronic kidney disease

\begin{tabular}{cc}
\hline \multicolumn{3}{c}{ Microdose } \\
\hline GM & GMR \\
$(95 \% \mathrm{Cl})$ & $(95 \% \mathrm{Cl})$
\end{tabular}

\begin{tabular}{cc}
\multicolumn{3}{c}{ disease } \\
\hline \multicolumn{3}{c}{ Microdose } \\
\hline GM & GMR \\
$(95 \% \mathrm{Cl})$ & $(95 \% \mathrm{Cl})$
\end{tabular}

${ }^{a}$ Data are presented in the median (interquartile range).

${ }^{*} \mathrm{p}$-value $<0.05$, healthy young adult as a reference group.

"p-value $<0.05$, healthy elderly as a reference group.

$A \cup C_{\text {o-last: }}$ area under the concentration-time curve of time zero to the last time point; Cl: confidence interval; $C L / F$ : oral clearance; $C L_{R}:$ renal clearance; $C_{m a x}:$ maximum plasma

concentration; GM: geometric mean; GMR: geometric mean ratio; $T_{\max }$ : time to maximum plasma concentration; $T_{1 / 2}$ : half-life.

microdose cocktail has been validated in Caucasians, showing a potential of simultaneous assessment for enzyme and drug transporter activity (Prueksaritanont et al., 2017). Here, we verified the utilization of the cocktail in the Thai population. Our microdose cocktail-RIF drug-drug interaction study in the Thai population showed similar findings as reported in the earlier study (Prueksaritanont et al., 2017).

Reductions in CYP3A activity were observed with similar magnitude in both elderly with or without CKD, shown by the increased $A U C$ and $C_{\max }$ and prolonged $T_{1 / 2}$ of $M D Z$. It should be noted that oral MDZ as a probe drug represents CYP3A activity in both intestine and liver and that the change in MDZ pharmacokinetics found in this study could be attributed to changes in intestinal and/or hepatic CYP3A activity. Additionally, as MDZ is an intermediate hepatic extraction drug, a physiological reduction of hepatic blood flow anticipated in the elderly might also contribute to the observed reduction in hepatic clearance of $\mathrm{MDZ}$ (Dundee et al., 1986; Amrein and Hetzel, 1990). Our finding that CKD was not associated with changes in pharmacokinetic profiles of MDZ was consistent with a previous study where neither AUC nor $\mathrm{C}_{\max }$ of $\mathrm{MDZ}$ was affected by renal impairment (Tatosian et al., 2020).

Genetic polymorphisms of the CYP3A gene were reported in the Thai population (Mauleekoonphairoj et al., 2020). CYP3A4 polymorphisms are rarely found in Asians, whereas $65-85 \%$ of Asians have CYP3A5*3 (Lamba et al., 2002; Hutchison and O'Brien, 2007; Zhou et al., 2017; Mauleekoonphairoj et al., 2020). Although some studies indicated that polymorphisms of CYP3A4/5 might affect the clearance of their substrate such as tacrolimus, the genetic variation in CYP3A enzymes has no significant correlation with in vivo MDZ metabolism and disposition (He et al., 2005; Miao et al., 2009; Singh et al., 2009). Here, CYP3A5*3 genotyping and pharmacokinetic parameters analysis were also assessed (Supplementary Table S3). The results showed that elderly patients with CKD who were with wildtype CYP3A5 $(n=5)$ had increased AUC and $\mathrm{C}_{\max }$ of MDZ (GMR 2.0-3.0) when compared to healthy young participants with wild-type CYP3A5 ( $n=5$, Supplementary Table S6). This magnitude of increases in $\mathrm{AUC}$ and $\mathrm{C}_{\max }$ of $\mathrm{MDZ}$ in participants with wild-type CYP3A5 was similar to that in 
TABLE 5 | Multivariate analysis of the differences in $\mathrm{AUC}_{0-\text { last }}, \mathrm{C}_{\max }$, and $\mathrm{T}_{1 / 2}$ between three groups of participants.

\begin{tabular}{|c|c|c|c|c|c|c|c|}
\hline Multivariate model & Midazolam & Dabigatran & Pitavastatin $^{a}$ & $\begin{array}{l}\text { Pitavastatin } \\
\text { lactone }^{a}\end{array}$ & Atorvastatin $^{a}$ & $\begin{array}{c}\text { 4-Hydroxy } \\
\text { atorvastatin }^{a}\end{array}$ & Rosuvastatin ${ }^{\mathbf{b}}$ \\
\hline $\mathrm{N}$ & 53 & 53 & 52 & 52 & 52 & 52 & 29 \\
\hline \multicolumn{8}{|l|}{ AUC $_{0 \text {-last }}$} \\
\hline Healthy young adults & 1.00 & 1.00 & 1.00 & 1.00 & 1.00 & 1.00 & 1.00 \\
\hline Healthy elderly & $\begin{array}{c}2.19 \\
(1.61-2.98)^{\star \star}\end{array}$ & $\begin{array}{c}1.48 \\
(1.06-2.05)^{\star}\end{array}$ & $0.99(0.79-1.25)$ & $\begin{array}{c}1.25 \\
(0.99-1.57)\end{array}$ & $\begin{array}{c}2.00 \\
(1.41-2.85)^{\star \star}\end{array}$ & $\begin{array}{c}1.54 \\
(1.10-2.14)^{\star}\end{array}$ & $\begin{array}{c}2.02 \\
(1.16-3.51)^{\star}\end{array}$ \\
\hline Elderly with CKD & $\begin{array}{c}2.68 \\
(1.95-3.68)^{\star \star}\end{array}$ & $\begin{array}{c}3.80 \\
(2.72-5.31)^{\star \star}\end{array}$ & $\begin{array}{c}1.57 \\
(1.26-1.97)^{\star \star}\end{array}$ & $\begin{array}{c}2.16 \\
(1.70-2.74)^{\star \star}\end{array}$ & $\begin{array}{c}4.15 \\
(2.62-5.32)^{\star \star}\end{array}$ & $\begin{array}{c}2.55 \\
(1.82-3.56)^{\star \star}\end{array}$ & $\begin{array}{c}2.09 \\
(1.26-3.49)^{\star}\end{array}$ \\
\hline $\begin{array}{l}\text { Elderly with CKD vs } \\
\text { Healthy elderly }\end{array}$ & $\begin{array}{c}1.22 \\
(0.89-1.67)\end{array}$ & $\begin{array}{c}2.58 \\
(1.85-3.59)^{\star \star}\end{array}$ & $\begin{array}{c}1.59 \\
(1.26-2.01)^{\star \star}\end{array}$ & $\begin{array}{c}1.73 \\
(1.37-2.18)^{\star \star}\end{array}$ & $\begin{array}{c}1.86 \\
(1.30-2.66)^{\star}\end{array}$ & $\begin{array}{c}1.66 \\
(1.17-2.34)^{\star}\end{array}$ & $1.04(0.57-1.88)$ \\
\hline Body weight & - & - & - & $\begin{array}{c}0.98 \\
(0.98-0.99)^{\star \star}\end{array}$ & - & - & - \\
\hline Albumin & - & - & $\begin{array}{c}0.64 \\
(0.41-1.00)^{\star}\end{array}$ & - & - & - & - \\
\hline Total bilirubin & - & - & - & $\begin{array}{c}0.79 \\
(0.64-0.99)^{\star}\end{array}$ & - & - & - \\
\hline \multicolumn{8}{|l|}{$\mathrm{C}_{\max }$} \\
\hline Healthy young adults & 1.00 & 1.00 & 1.00 & 1.00 & 1.00 & 1.00 & 1.00 \\
\hline Healthy elderly & $\begin{array}{c}1.83 \\
(1.40-2.38)^{\star \star}\end{array}$ & $\begin{array}{c}1.30 \\
(0.99-1.71)\end{array}$ & $1.02(0.80-1.31)$ & $\begin{array}{c}1.06 \\
(0.89-1.27)\end{array}$ & $\begin{array}{c}2.15 \\
(1.41-3.27)^{\star}\end{array}$ & $\begin{array}{c}1.32 \\
(0.97-1.79)\end{array}$ & $\begin{array}{c}1.69 \\
(1.11-2.55)^{\star}\end{array}$ \\
\hline Elderly with CKD & $\begin{array}{c}1.86 \\
(1.42-2.44)^{\star \star}\end{array}$ & $\begin{array}{c}1.91 \\
(1.43-2.56)^{\star \star}\end{array}$ & $\begin{array}{c}1.78 \\
(1.38-2.30)^{\star \star}\end{array}$ & $\begin{array}{c}1.63 \\
(1.35-1.96)^{\star \star}\end{array}$ & $\begin{array}{c}3.98 \\
(2.61-6.08)^{\star \star}\end{array}$ & $\begin{array}{c}1.71 \\
(1.26-2.33)^{\star}\end{array}$ & $\begin{array}{c}1.92 \\
(1.28-2.87)^{\star}\end{array}$ \\
\hline $\begin{array}{l}\text { Elderly with CKD vs } \\
\text { Healthy elderly }\end{array}$ & $\begin{array}{c}1.02 \\
(0.77-1.34)\end{array}$ & $\begin{array}{c}1.47 \\
(1.10-1.96)^{\star}\end{array}$ & $\begin{array}{c}1.74 \\
(1.36-2.24)^{\star \star}\end{array}$ & $\begin{array}{c}1.53 \\
(1.28-1.84)^{\star \star}\end{array}$ & $\begin{array}{c}1.85 \\
(1.21-2.83)^{\star}\end{array}$ & $\begin{array}{c}1.30 \\
(0.94-1.79)\end{array}$ & $1.14(0.73-1.78)$ \\
\hline Body weight & - & $\begin{array}{c}0.98 \\
(0.97-0.99)^{\star \star}\end{array}$ & $\begin{array}{c}0.98 \\
(0.97-0.99)^{\star \star}\end{array}$ & $\begin{array}{c}0.98 \\
(0.98-0.99)^{\star \star}\end{array}$ & - & - & $\begin{array}{c}0.98 \\
(0.97-0.99)^{\star}\end{array}$ \\
\hline \multicolumn{8}{|l|}{$T_{1 / 2}$} \\
\hline Healthy young adults & 1.00 & 1.00 & & & & & \\
\hline Healthy elderly & $\begin{array}{c}2.31 \\
(1.72-3.10)^{\star \star}\end{array}$ & $\begin{array}{c}1.15 \\
(0.93-1.44)\end{array}$ & & & & & \\
\hline Elderly with CKD & $\begin{array}{c}2.52 \\
(1.89-3.36)^{\star \star}\end{array}$ & $\begin{array}{c}2.93 \\
(2.35-3.64)^{\star \star}\end{array}$ & & & & & \\
\hline Elderly with CKD vs & 1.09 & 2.54 & & & & & \\
\hline Healthy elderly & $(0.80-1.48)$ & $(2.01-3.19)^{\star \star}$ & & & & & \\
\hline
\end{tabular}

Data are presented in the geometric mean ratio (95\% confidence interval).

Variables with a $\mathrm{p}$-value $<0.1$ in the univariate analysis were included in the multivariable analysis.

${ }^{a}$ A subject with SLCO1B1 wild-type's plasma drug concentration was an outlier and was excluded from the model.

${ }^{b}$ Twenty four subjects with ABCG2 variants (rs2231142, 421AA and 421CA) were excluded from the model.

${ }^{*} \mathrm{p}<0.05,{ }^{* *} \mathrm{p}<0.001$.

$A \cup C_{0-\text { last: }}$ area under the concentration-time curve of time zero to the last time point; $C_{\text {max }}$ maximum plasma concentration; $C K D$ : chronic kidney disease; $T_{1 / 2}$ : half-life.

all other participants studied (Table 2). The comparison between wild-type and variant genotypes of CYP3A5 within the group of healthy young participants was also analyzed, and no significant difference was observed (Supplementary Table S7). Therefore, the genetic variations of the CYP3A5 enzyme did not affect the pharmacokinetics of MDZ in our study.

A widely used probe substrate for an intestinal efflux transporter P-gp is DABE. DABE is rapidly converted to DABI after absorption (Chu et al., 2018). The reduction of P-gp activity may decrease the efflux of DABE in the intestine, increasing plasma DABI levels (Chu et al., 2018). In this study, the AUC of DABI was increased in the elderly both with and without CKD compared to healthy young adults. Considering that DABI is $80 \%$ excreted into the urine in an unchanged form (MuñozCorcuera et al., 2016), $\mathrm{CL}_{\mathrm{R}}$ of DABI was measured. The magnitude of DABI's AUC augmentation was prominent in elderly patients with $\mathrm{CKD}$, corresponding with a more significant $C_{R}$ reduction (Table 2). Compared to healthy young participants, the theoretical AUCRs for DABI in healthy elderly and elderly patients with CKD were increased by 1.47 and 2.84 fold, respectively. These data suggested that ageing may not affect intestinal P-gp function since the observed AUCR for DABI of healthy elderly in our study (1.46 fold, Table 2) was closed to the theoretical AUCR (1.47 fold). However, intestinal P-gp is possibly affected by CKD as the observed AUCR for DABI in elderly patients with CKD (4.26 fold, Table 2) is much higher than the theoretical AUCR (2.84 fold). By this, intestinal P-gp function might be impaired, leading to an approximately 1.42 fold increase in AUCR for DABI in elderly patients with CKD. Likewise, a previous study also reported no significant AUC elevation of digoxin, another probe substrate of P-gp at intestinal and systemic levels in the elderly, compared to young adults (Larsen et al., 2007). Reports in a rat model also suggested a downregulation of intestinal P-gp activity in CKD associated with increased drug absorption (Veau et al., 2001; Naud et al., 2007). The latest clinical study in CKD 
(Tatosian et al., 2020) observed a progressive increase in $\mathrm{AUC}_{0 \text {-inf }}$ and $\mathrm{C}_{\max }$ of DABI with increasing severity of renal impairment up to 4.9 and 1.7 fold, respectively, which is in keeping with our data. Their findings were confirmed with the co-administration of RIF. Here, we also showed that elderly patients with CKD had increased AUC of DABI and the change in AUCRs supports a reduction of intestinal $\mathrm{P}$-gp activity in renal failure. However, unlike the AUC, an increase in $\mathrm{C}_{\max }$ of DABI in elderly patients with CKD compared to healthy elderly did not reach statistical significance. Hence, the intestinal P-gp activity in CKD might not be meaningfully affected.

OATP1B is an uptake drug transporter in the liver, where PTV is a probe substrate for this transporter (Prueksaritanont et al., 2014). OATP1B transfers PTV from the portal vein into hepatocytes. PTV is not a significant substrate of human CYP450 but mainly undergoes rapid glucuronidation by UDPglycosyltransferase 1A1 (UGT1A1), UGT1A2, and UGT2B7 to PTV-lactone. Unlike PTV, PTV lactone is not a substrate for OATP1B (Alagona, 2010). The reduction of OATP1B activity can increase plasma drug levels of an OATP1B substrate (Shitara, 2011). In our study, only OATP1B activity in the elderly patients with CKD declined compared to healthy young participants and healthy elderly, as demonstrated by increased AUC and $\mathrm{C}_{\max }$ of PTV (Table 3). This finding is consistent with a previous pharmacokinetic study in patients with non-hemodialysis moderate and severe renal impairment (Morgan et al., 2012). A reduction in OATP1B transporter expression and activity was reported in CKD rat models (Sun et al., 2006; Naud et al., 2008). Additionally, a physiologically-based pharmacokinetic (PBPK) study showed a $60 \%$ reduction in hepatic OATP1B transporter activity in patients with severe CKD (Tan et al., 2019). Our findings were different from Tatosian, et al. (Tatosian et al., 2020) as we also observed an increase in AUC and $\mathrm{C}_{\max }$ of PTV-lactone, and no differences were found with the $\mathrm{AUC}_{0 \text {-last }}$ of PTV-lactone/ PTV ratio in the elderly patients with CKD (Table 3). The underlying reasons for the discrepancy between the two studies remain unclear.

BCRP is an intestinal efflux transporter capable of reducing systemic exposure of many oral drugs and substrates, including RSV (Huang et al., 2006). Consistent with other studies (Zhang et al., 2006; Keskitalo et al., 2009; Lee et al., 2013), we found that polymorphisms of $A B C G 2$ affected pharmacokinetic profiles of RSV as evidenced by increased AUC and $C_{\max }$ of RSV in participants with $A B C G 2$ variant (Supplementary Table S5). After excluding the participants with this genetic confounder, we observed a significant increase in AUC of RSV in healthy elderly and a more prominent increase of AUC in elderly patients with CKD (Table 4). In addition, the observed AUCRs of RSV in healthy elderly and elderly patients with CKD when compared to healthy young adults were 2.02 and 2.09 fold, respectively (Table 4), which were higher than the theoretical AUCRs of RSV (1.19 fold in healthy elderly and 1.32 fold in elderly patients with $\mathrm{CKD}$ ). This finding suggested that BCRP transporter activity might be affected by both ageing and CKD. However, a more significant effect on $\mathrm{C}_{\max }$ of RSV in healthy elderly and elderly patients with CKD should have occurred if intestinal BCRP transporter activity was reduced (Table 4). Hence, an association of ageing and $\mathrm{CKD}$ with BCRP represented by changes in pharmacokinetic profiles of RSV still cannot be entirely determined in our study. Other studies reported no association between ageing and RSV exposure (Martin et al., 2002; Davidson, 2007; Kim et al., 2019). Our data is consistent with Tatosian, et al. (Tatosian et al., 2021) where RSV pharmacokinetics alteration was not associated with CKD. In addition, RSV is another substrate of hepatic OATP1B transporter but is less sensitive and less selective than PTV (Prueksaritanont et al., 2014). Therefore, when considering the pharmacokinetic changes of RSV with PTV results as discussed above, a definitive effect of CKD on hepatic OATP1B transporter activity is still yet to be concluded.

ATV is mainly metabolized by CYP3A and transported by hepatic OATP1B (major), intestinal BCRP, and possibly, to a minor extent, intestinal P-gp (Kellick et al., 2014; Kellick, 2017). Here, we found a significant increase in AUC and $\mathrm{C}_{\text {max. }}$ of ATV associated with ageing and $\mathrm{CKD}$. The pharmacokinetic changes of ATV were in support of the pharmacokinetic changes seen with MDZ. CYP3A4 converts ATV into its major metabolite, 4$\mathrm{OH}-\mathrm{ATV}$ (Hoffart et al., 2012). A reduction in the $\mathrm{AUC}_{0 \text {-last }}$ ratio for 4-OH-ATV/ATV and the association of ageing and changes in ATV plasma levels observed in this study (Table 4) was in line with findings observed with MDZ on CYP3A. The effect of ageing on pharmacokinetic profiles of ATV (Table 4) is similar to a previous report of reduced CYP3A enzyme activity in ageing (Gibson et al., 1996).

On the other hand, the effects of CKD on pharmacokinetic profiles of ATV and its metabolite in our study were inconclusive. In the recent study by Tatosian, et, al., increases in AUC and $\mathrm{C}_{\max }$ of ATV were associated with the severity of renal impairment (Tatosian et al., 2020). Therefore, P-gp and BCRP may be additional factors involved in alterations of ATV pharmacokinetics in elderly patients with CKD. Unfortunately, BCRP activity was inconclusive in our study due to the results of RSV as discussed above.

It is important to note that although age- and CKD-associated changes in OATP1B and BCRP drug transporter activity could not be definitively concluded, our results suggest a trend in their changes. Furthermore, these findings are potentially beneficial to clinicians as most older people are generally taking multiple drug treatments and are therefore at risk of drug-drug interactions.

It is also worth noting that our study did not directly measure unbound plasma concentrations due to the assay sensitivity limitation. However, plasma protein binding was indirectly determined by ex-vivo experiments using pooled predose plasma samples from each study group, spiked with relevant plasma concentrations of substrates $(5-30 \mathrm{ng} / \mathrm{ml})$. No significant difference of unbound fraction amongst the three studied groups was found for all drugs used in this cocktail (data not shown). These data suggested a negligible effect of plasma protein binding in our study, and consequently, similar conclusions would be expected with unbound drug pharmacokinetics. Currently, efforts are underway to develop a PBPK model using data from this study to delineate the effect of ageing and CKD on the underlying mechanisms related to drug metabolizing enzymes and drug transporters in elderly patients with CKD. 
This study has limitations. In general, gender could affect the pharmacokinetics of drugs because of the differences in their physiology. For instance, women usually have lower body weight, lower muscle mass, and less intestinal enzymatic activity than men (Whitley and Lindsey, 2009). Although participants in this study were not intentionally matched by gender, which is one of our limitations, the significant difference in pharmacokinetic parameters was not found after gender adjustment in the multivariable analysis. Total body weight determines body composition (lean weight: adipose weight), affecting the volume distribution of drugs (Muñoz-Corcuera et al., 2016). A significant difference in body weight was seen at baseline between healthy young participants and elderly patients with $\mathrm{CKD}$, but no effect of body weight on pharmacokinetic of drugs was found in the multivariate analysis. We have also carried out a subgroup analysis stratified by severity of $\mathrm{CKD}$, and there was no significant difference shown between moderate and severe renal impairment (data not shown). No potential pharmacokinetic drug-drug interaction was observed between concomitant drugs and probe drugs. However, the screening for pharmacodynamics drug-drug interaction has not been performed.

Additionally, further studies with larger cohort sizes that stratify based on CKD severity, together with patients on dialysis and RIF co-administration in all study populations, may be warranted. Population pharmacokinetic studies would be helpful to elucidate if and how other factors affect the pharmacokinetics of the probe drugs profiles. Finally, PBPK studies using data from this study would provide more information to inform predictions of changes in drug metabolizing enzymes and drug transporter activity in elderly patients with CKD.

In conclusion, the microdose cocktail approach provides a valuable and safe screening tool to determine pharmacokinetic parameter alterations showing reduced CYP3A activity in the elderly. Intestinal P-gp activity might be reduced in $\mathrm{CKD}$, but as the results in AUCR and $\mathrm{C}_{\max }$ were conflicting, this has to be confirmed in further studies. Health care providers should be aware of the potential consequences of administering CYP3A and intestinal P-gp substrates or inhibitors to these target populations.

\section{DATA AVAILABILITY STATEMENT}

The original contributions presented in the study are included in the article/Supplementary Material, further inquiries can be directed to the corresponding author.

\section{REFERENCES}

Alagona, P., Jr. (2010). Pitavastatin: Evidence for its Place in Treatment of Hypercholesterolemia. Core Evid. 5, 91-105. doi:10.2147/CE.S8008

Alexander, S. P., Kelly, E., Marrion, N. V., Peters, J. A., Faccenda, E., Harding, S. D., et al. (2017). The Concise Guide to Pharmacology 2017/18: Overview. Br. J. Pharmacol. 174 (Suppl. 1), S1-s16. doi:10.1111/bph.13882

American Geriatrics Society Beers Criteria ${ }^{\circledR}$ Update Expert Panel (2019). American Geriatrics Society 2019 Updated AGS Beers Criteria ${ }^{\circledR}$ for Potentially Inappropriate Medication Use in Older Adults. J. Am. Geriatr. Soc. 67, 674-694. doi:10.1111/jgs.15767

\section{ETHICS STATEMENT}

The studies involving human participants were reviewed and approved by The Institutional Review Board of the Faculty of Medicine, Chulalongkorn University, Bangkok, Thailand. The patients/participants provided their written informed consent to participate in this study.

\section{AUTHOR CONTRIBUTIONS}

PR, TP, UU, SJ, YA, and PC: study design and study planning. PR, $\mathrm{WK}, \mathrm{NT}, \mathrm{SU}, \mathrm{KP}$, and YA: participant recruitment and conducting the clinical part of the study. TT, UU, and TP: conducting the bioanalysis part of the study. PR, SK, TP, and PC: conducting pharmacokinetic and statistical parts of the study. SJ, BO, UU, and TP: funding applications. PR: draft the manuscript. SK, WK, NT, SU, KP, TT, UU, SJ, BO, TP, YA, and PC: finalized the manuscript.

\section{FUNDING}

Funding of this work was provided by Health Systems Research Institute (HSRI) grant no. 60094. PR was supported by the 100th Anniversary Chulalongkorn University Fund for Doctoral Scholarship. Funds received for open access publication fees is from corresponding author.

\section{ACKNOWLEDGMENTS}

We thank all participants who took part in this study. We also thank the clinical research staff of Maha Chakri Sirindhorn Clinical Research Center Under the Royal Patronage, Research Affairs, Faculty of Medicine, Chulalongkorn University, Bangkok, Thailand, for their clinical research support.

\section{SUPPLEMENTARY MATERIAL}

The Supplementary Material for this article can be found online at: https://www.frontiersin.org/articles/10.3389/fphar.2021.726669/ full\#supplementary-material

Amrein, R., and Hetzel, W. (1990). Pharmacology of Dormicum (Midazolam) and Anexate (Flumazenil). Acta Anaesthesiol Scand. Suppl. 92, 6-47. doi:10.1111/ j.1399-6576.1990.tb03174.x

Blech, S., Ebner, T., Ludwig-Schwellinger, E., Stangier, J., and Roth, W. (2008). The Metabolism and Disposition of the Oral Direct Thrombin Inhibitor, Dabigatran, in Humans. Drug Metab. Dispos 36, 386-399. doi:10.1124/dmd.107.019083

Center for Drug Evaluation and Research (Cder) U.S. Department of Health and Human Sciences Food and Drug Administration (2020). Clinical Drug Interaction Studies Cytochrome P460 Enzyme- and Transporter-Mediated Drug Interactions: Guidance for Industry

Chu, X., Galetin, A., Zamek-Gliszczynski, M. J., Zhang, L., and Tweedie, D. J. (2018). Dabigatran Etexilate and Digoxin: Comparison as Clinical Probe 
Substrates for Evaluation of P-Gp Inhibition. Clin. Pharmacol. Ther. 104, 788-792. doi:10.1002/cpt.1213

Dagli, R. J., and Sharma, A. (2014). Polypharmacy: a Global Risk Factor for Elderly People. J. Int. Oral Health 6, i-ii.

Davidson, M. H. (2007). Rosuvastatin in Elderly Patients. Drugs Aging 24, 933-944. doi:10.2165/00002512-200724110-00005

Dundee, J. W., Collier, P. S., Carlisle, R. J., and Harper, K. W. (1986). Prolonged Midazolam Elimination Half-Life. Br. J. Clin. Pharmacol. 21, 425-429. doi:10.1111/j.1365-2125.1986.tb05217.x

Eldesoky, E. S. (2007). Pharmacokinetic-pharmacodynamic Crisis in the Elderly. Am. J. Ther. 14, 488-498. doi:10.1097/01.mjt.0000183719.84390.4d

European Medicines Agency (2012). Guideline on the Investigation of Drug Interactions.

Fuhr, U., Hsin, C. H., Li, X., Jabrane, W., and Sörgel, F. (2019). Assessment of Pharmacokinetic Drug-Drug Interactions in Humans: In Vivo Probe Substrates for Drug Metabolism and Drug Transport Revisited. Annu. Rev. Pharmacol. Toxicol. 59, 507-536. doi:10.1146/annurev-pharmtox010818-021909

Giacomini, K. M., Giacomini, K. M., Huang, S. M., Tweedie, D. J., Benet, L. Z., Brouwer, K. L., et al. (2010). Membrane Transporters in Drug Development. Nat. Rev. Drug Discov. 9, 215-236. doi:10.1038/nrd3028

Gibson, D. M., Bron, N. J., Richens, A., Hounslow, N. J., Sedman, A. J., and Whitfield, L. R. (1996). Effect of Age and Gender on Pharmacokinetics of Atorvastatin in Humans. J. Clin. Pharmacol. 36, 242-246. doi:10.1002/j.15524604.1996.tb04194.x

He, P., Court, M. H., Greenblatt, D. J., and Von Moltke, L. L. (2005). Genotypephenotype Associations of Cytochrome P450 3A4 and 3A5 Polymorphism with Midazolam Clearance In Vivo. Clin. Pharmacol. Ther. 77, 373-387. doi:10.1016/ j.clpt.2004.11.112

Hoffart, E., Ghebreghiorghis, L., Nussler, A. K., Thasler, W. E., Weiss, T. S., Schwab, M., et al. (2012). Effects of Atorvastatin Metabolites on Induction of Drug-Metabolizing Enzymes and Membrane Transporters through Human Pregnane X Receptor. Br. J. Pharmacol. 165, 1595-1608. doi:10.1111/j.14765381.2011.01665.X

Huang, L., Wang, Y., and Grimm, S. (2006). ATP-dependent Transport of Rosuvastatin in Membrane Vesicles Expressing Breast Cancer Resistance Protein. Drug Metab. Dispos 34, 738-742. doi:10.1124/dmd.105.007534

Hutchison, L. C., and O'brien, C. E. (2007). Changes in Pharmacokinetics and Pharmacodynamics in the Elderly Patient. J. Pharm. Pract. 20, 4-12. doi:10.1177/0897190007304657

Ingsathit, A., Thakkinstian, A., Chaiprasert, A., Sangthawan, P., Gojaseni, P., Kiattisunthorn, K., et al. (2009). Prevalence and Risk Factors of Chronic Kidney Disease in the Thai Adult Population: Thai SEEK Study. Nephrol. Dial. Transpl. 25, 1567-1575. doi:10.1093/ndt/gfp669

Kellick, K. (2017). Organic Ion Transporters and Statin Drug Interactions. Curr. Atheroscler. Rep. 19, 65. doi:10.1007/s11883-017-0701-y

Kellick, K. A., Bottorff, M., and Toth, P. P. (2014). The National Lipid Association's Safety Task, F.A Clinician's Guide to Statin Drug-Drug Interactions. J. Clin. Lipidol. 8, S30-S46. doi:10.1016/j.jacl.2014.02.010

Keskitalo, J. E., Zolk, O., Fromm, M. F., Kurkinen, K. J., Neuvonen, P. J., and Niemi, M. (2009). ABCG2 Polymorphism Markedly Affects the Pharmacokinetics of Atorvastatin and Rosuvastatin. Clin. Pharmacol. Ther. 86, 197-203. doi:10.1038/clpt.2009.79

Kim, Y., Yoon, S., Choi, Y., Yoon, S. H., Cho, J. Y., Jang, I. J., et al. (2019). Influence of OATP1B1 and BCRP Polymorphisms on the Pharmacokinetics and Pharmacodynamics of Rosuvastatin in Elderly and Young Korean Subjects. Sci. Rep. 9, 19410. doi:10.1038/s41598-019-55562-4

Klotz, U. (2009). Pharmacokinetics and Drug Metabolism in the Elderly. Drug Metab. Rev. 41, 67-76. doi:10.1080/03602530902722679

Lamba, J. K., Lin, Y. S., Schuetz, E. G., and Thummel, K. E. (2002). Genetic Contribution to Variable Human CYP3A-Mediated Metabolism. Adv. Drug Deliv. Rev. 54, 1271-1294. doi:10.1016/s0169-409x(02)00066-2

Larsen, U. L., Hyldahl Olesen, L., Guldborg Nyvold, C., Eriksen, J., Jakobsen, P., Østergaard, M., et al. (2007). Human Intestinal P-Glycoprotein Activity Estimated by the Model Substrate Digoxin. Scand. J. Clin. Lab. Invest. 67, 123-134. doi:10.1080/00365510600986084

Lee, H. K., Hu, M., Lui, S. Sh., Ho, C. S., Wong, C. K., and Tomlinson, B. (2013). Effects of Polymorphisms in ABCG2, SLCO1B1, SLC10A1 and CYP2C9/19 on
Plasma Concentrations of Rosuvastatin and Lipid Response in Chinese Patients. Pharmacogenomics 14, 1283-1294. doi:10.2217/pgs.13.115

Lynch, T., and Price, A. (2007). The Effect of Cytochrome P450 Metabolism on Drug Response, Interactions, and Adverse Effects. Am. Fam. Physician 76, 391-396.

Martin, P. D., Dane, A. L., Nwose, O. M., Schneck, D. W., and Warwick, M. J. (2002). No Effect of Age or Gender on the Pharmacokinetics of Rosuvastatin: a New HMG-CoA Reductase Inhibitor. J. Clin. Pharmacol. 42, 1116-1121. doi:10.1177/009127002401382722

Mauleekoonphairoj, J., Chamnanphon, M., Khongphatthanayothin, A., Sutjaporn, B., Wandee, P., Poovorawan, Y., et al. (2020). Phenotype Prediction and Characterization of 25 Pharmacogenes in Thais from Whole Genome Sequencing for Clinical Implementation. Sci. Rep. 10, 18969. doi:10.1038/ s41598-020-76085-3

Miao, J., Jin, Y., Marunde, R. L., Gorski, C. J., Kim, S., Quinney, S., et al. (2009). Association of Genotypes of the CYP3A Cluster with Midazolam Disposition In Vivo. Pharmacogenomics J. 9, 319-326. doi:10.1038/tpj.2009.21

Morgan, R. E., Campbell, S. E., Yu, C. Y., Sponseller, C. A., and Muster, H. A. (2012). Comparison of the Safety, Tolerability, and Pharmacokinetic Profile of a Single Oral Dose of Pitavastatin $4 \mathrm{Mg}$ in Adult Subjects with Severe Renal Impairment Not on Hemodialysis versus Healthy Adult Subjects. J. Cardiovasc. Pharmacol. 60, 42-48. doi:10.1097/FJC.0b013e318256cdf0

Muñoz-Corcuera, M., Ramírez-Martínez-Acitores, L., López-Pintor, R. M., Casañas-Gil, E., and Hernández-Vallejo, G. (2016). Dabigatran: A New Oral Anticoagulant. Guidelines to Follow in Oral Surgery Procedures. A Systematic Review of the Literature. Med. Oral Patol Oral Cir Bucal 21, e679-e688. doi:10.4317/medoral.21202

Naud, J., Michaud, J., Boisvert, C., Desbiens, K., Leblond, F. A., Mitchell, A., et al. (2007). Down-regulation of Intestinal Drug Transporters in Chronic Renal Failure in Rats. J. Pharmacol. Exp. Ther. 320, 978-985. doi:10.1124/jpet.106.112631

Naud, J., Michaud, J., Leblond, F. A., Lefrancois, S., Bonnardeaux, A., and Pichette, V. (2008). Effects of Chronic Renal Failure on Liver Drug Transporters. Drug Metab. Dispos 36, 124-128. doi:10.1124/dmd.107.018192

Nolin, T. D., Naud, J., Leblond, F. A., and Pichette, V. (2008). Emerging Evidence of the Impact of Kidney Disease on Drug Metabolism and Transport. Clin. Pharmacol. Ther. 83, 898-903. doi:10.1038/clpt.2008.59

Praditpornsilpa, K., Townamchai, N., Chaiwatanarat, T., Tiranathanagul, K., Katawatin, P., Susantitaphong, P., et al. (2011). The Need for Robust Validation for MDRD-Based Glomerular Filtration Rate Estimation in Various CKD Populations. Nephrol. Dial. Transpl. 26, 2780-2785. doi:10.1093/ndt/gfq815

Prueksaritanont, T., Chu, X., Evers, R., Klopfer, S. O., Caro, L., Kothare, P. A., et al. (2014). Pitavastatin Is a More Sensitive and Selective Organic AnionTransporting Polypeptide 1B Clinical Probe Than Rosuvastatin. Br. J. Clin. Pharmacol. 78, 587-598. doi:10.1111/bcp.12377

Prueksaritanont, T., Tatosian, D. A., Chu, X., Railkar, R., Evers, R., Chavez-Eng, C., et al. (2017). Validation of a Microdose Probe Drug Cocktail for Clinical Drug Interaction Assessments for Drug Transporters and CYP3A. Clin. Pharmacol. Ther. 101, 519-530. doi:10.1002/cpt.525

Ramsey, L. B., Johnson, S. G., Caudle, K. E., Haidar, C. E., Voora, D., Wilke, R. A., et al. (2014). The Clinical Pharmacogenetics Implementation Consortium Guideline for SLCO1B1 and Simvastatin-Induced Myopathy: 2014 Update. Clin. Pharmacol. Ther. 96, 423-428. doi:10.1038/clpt.2014.125

Rattanacheeworn, P., Chamnanphon, M., Thongthip, S., Kittanamongkolchai, W., Townamchai, N., Avihingsanon, Y., et al. (2020). SLCO1B1 and ABCG2 Gene Polymorphisms in a Thai Population. Pharmgenomics Pers Med. 13, 521-530. doi:10.2147/PGPM.S268457

Romaine, S. P., Bailey, K. M., Hall, A. S., and Balmforth, A. J. (2010). The Influence of SLCO1B1 (OATP1B1) Gene Polymorphisms on Response to Statin Therapy. Pharmacogenomics J. 10, 1-11. doi:10.1038/tpj.2009.54

Shitara, Y. (2011). Clinical Importance of OATP1B1 and OATP1B3 in Drug-Drug Interactions. Drug Metab. Pharmacokinet. 26, 220-227. doi:10.2133/ dmpk.DMPK-10-RV-094

Singh, R., Srivastava, A., Kapoor, R. K. S., and D Mittal, R. (2009). Impact of CYP3A5 and CYP3A4 Gene Polymorphisms on Dose Requirement of Calcineurin Inhibitors, Cyclosporine and Tacrolimus, in Renal Allograft Recipients of North India. Naunyn Schmiedebergs Arch. Pharmacol. 380, 169-177. doi:10.1007/s00210-009-0415-y

Sun, H., Frassetto, L., and Benet, L. Z. (2006). Effects of Renal Failure on Drug Transport and Metabolism. Pharmacol. Ther. 109, 1-11. doi:10.1016/j.pharmthera.2005.05.010 
Tan, M. L., Zhao, P., Zhang, L., Ho, Y. F., Varma, M. V. S., Neuhoff, S., et al. (2019). Use of Physiologically Based Pharmacokinetic Modeling to Evaluate the Effect of Chronic Kidney Disease on the Disposition of Hepatic CYP2C8 and OATP1B Drug Substrates. Clin. Pharmacol. Ther. 105, 719-729. doi:10.1002/cpt.1205

Tatosian, D. A., Yee, K. L., Zhang, Z., Mostoller, K., Paul, E., Sutradhar, S., et al. (2020). A Microdose Cocktail to Evaluate Drug Interactions in Patients with Renal Impairment. Clin. Pharmacol. Ther. 109, 403. doi:10.1002/ cpt.1998

Tatosian, D. A., Yee, K. L., Zhang, Z., Mostoller, K., Paul, E., Sutradhar, S., et al. (2021). A Microdose Cocktail to Evaluate Drug Interactions in Patients with Renal Impairment. Clin. Pharmacol. Ther. 109, 403-415. doi:10.1002/ cpt.1998

Tieu, A., House, A. A., and Urquhart, B. L. (2016). Drug Disposition Issues in CKD: Implications for Drug Discovery and Regulatory Approval. Adv. Chronic Kidney Dis. 23, 63-66. doi:10.1053/j.ackd.2016.01.013

United Nations (2020). World Population Ageing 2019 (ST/ESA/SER.A/444). Departmet of Economic and Social Affairs, Population Division, United Nations.

U.S. Food and Drug Administration (2020). Drug Development and Drug Interactions: Table of Substrates, Inhibitors and Inducers. Available: https:// www.fda.gov/drugs/drug-interactions-labeling/drug-development-and-druginteractions-table-substrates-inhibitors-and-inducers (Accessed May 20, 2021).

Veau, C., Leroy, C., Banide, H., Auchère, D., Tardivel, S., Farinotti, R., et al. (2001). Effect of Chronic Renal Failure on the Expression and Function of Rat Intestinal P-Glycoprotein in Drug Excretion. Nephrol. Dial. Transpl. 16, 1607-1614. doi:10.1093/ndt/16.8.1607

Whitley, H., and Lindsey, W. (2009). Sex-based Differences in Drug Activity. Am. Fam. Physician 80, 1254-1258.

World Health Organization (2015). Older Population and Health System: a Profile of Thailand.
Yeung, C. K., Shen, D. D., Thummel, K. E., and Himmelfarb, J. (2014). Effects of Chronic Kidney Disease and Uremia on Hepatic Drug Metabolism and Transport. Kidney Int. 85, 522-528. doi:10.1038/ki.2013.399

Zhang, W., Yu, B. N., He, Y. J., Fan, L., Li, Q., Liu, Z. Q., et al. (2006). Role of BCRP 421C > A Polymorphism on Rosuvastatin Pharmacokinetics in Healthy Chinese Males. Clin. Chim. Acta 373, 99-103. doi:10.1016/j.cca.2006.05.010

Zhou, Y., Ingelman-Sundberg, M., and Lauschke, V. M. (2017). Worldwide Distribution of Cytochrome P450 Alleles: A Meta-Analysis of Population-Scale Sequencing Projects. Clin. Pharmacol. Ther. 102, 688-700. doi:10.1002/cpt.690

Conflict of Interest: The authors declare that the research was conducted in the absence of any commercial or financial relationships that could be construed as a potential conflict of interest.

Publisher's Note: All claims expressed in this article are solely those of the authors and do not necessarily represent those of their affiliated organizations, or those of the publisher, the editors and the reviewers. Any product that may be evaluated in this article, or claim that may be made by its manufacturer, is not guaranteed or endorsed by the publisher.

Copyright (C) 2021 Rattanacheeworn, Kerr, Kittanamongkolchai, Townamchai, Udomkarnjananun, Praditpornsilpa, Thanusuwannasak, Udomnilobol, Jianmongkol, Ongpipattanakul, Prueksaritanont, Avihingsanon and Chariyavilaskul. This is an open-access article distributed under the terms of the Creative Commons Attribution License (CC BY). The use, distribution or reproduction in other forums is permitted, provided the original author(s) and the copyright owner(s) are credited and that the original publication in this journal is cited, in accordance with accepted academic practice. No use, distribution or reproduction is permitted which does not comply with these terms. 